\title{
PENELUSURAN REFERENSI BERBASIS DIGITAL SEBAGAI PENINGKATAN SOFT SKILL MAHASISWA DALAM MENYELESAIKAN TUGAS AKHIR
}

\author{
Syaharuddin ${ }^{1)}$, Habib Ratu Perwira Negara²), Malik Ibrahim ${ }^{3)}$, Vera Mandailina ${ }^{1)}$, Dewi Pramita1), \\ Farah Heniati Santosa4) \\ 1)Pendidikan Matematika, Universitas Muhammadiyah Mataram, Mataram, Indonesia \\ 2)Teknik Informatika, Universitas Bumigora Mataram, Mataram, Indonesia \\ 3) Teknik Informatika, Universitas Nahdlatul Ulama NTB, Mataram, Indonesia \\ 4)Pendidikan Matematika, Universitas Nahdlatul Wathan Mataram, Mataram, Indonesia \\ Corresponding author: Syaharuddin \\ E-mail: syaharuddin.ntb@gmail.com
}

Diterima 8 Maret 2020, Disetujui 5 April 2020

\begin{abstract}
ABSTRAK
Tujuan dilaksanakan kegiatan ini yakni untuk meningkatkan soft skill mahasiswa dalam (1) menentukan topik penelitian yang akan diajukan sebagi tugas akhir (skripsi), (2) mempermudah mahasiswa dalam menelusuri hasil penelitian relevan yang mendukung penelitiannya, (3) menghindari kegiatan plagiasi selama penyusunan hasil penelitian, dan (4) memudahkan mahasiswa dalam menulis rujukan dan menyusun daftar pustaka. Kegiatan ini diikuti sebanyak 80 mahasiswa semester akhir. Workshop merupakan metode yang ideal dilakukan oleh tim abdimas sehingga berjalan dengan lancar. Pada tahap akhir, peserta mengisi angket Skala Likert dengan 4 option untuk mengukur pemahaman dan kemampuan mahasiswa selama workshop berlangsung. Hasil angket menunjukkan sebanyak $91,27 \%$ mahasiswa sudah paham terhadap strategi penyusunan dan menyelesiakan tugas akhir, sedangkan sisanya sebesar $8,73 \%$ belum paham pada bagian menentukan uji statistik yang digunakan untuk menjawab hipotesis penelitian.
\end{abstract}

Kata kunci: soft skill mahasiswa; referensi berbasis digital; penyusunan skripsi.

\section{ABSTRACT}

The purpose of this activity is to improve student soft skills in (1) determining research topics to be submitted as a final project (thesis), (2) making it easier for students to trace relevant research results that support their research, (3) avoiding plagiarism activities during the preparation of results research, and (4) make it easier for students to write references and compile bibliography. This activity was attended by 80 final semester students. The workshop is an ideal method carried out by the Abdimas team so that it runs smoothly. In the final stage, participants filled out a Likert Scale questionnaire with four options to measure students' understanding and ability during the workshop. The results of the questionnaire showed as much as $91.27 \%$ of students had understood the strategy of preparing and completing the final project, while the remaining $8.73 \%$ did not understand the part of determining the statistical test used to answer the research hypothesis.

Keywords: student soft skills; digital based reference; thesis compilation.

\section{PENDAHULUAN}

Mahasiswa adalah seorang akademisi yang memiliki kewajiban untuk menulis tugas akhir atau skripsi sebagai bentuk kontribusi terhadap keilmuanya. Ada dua tujuan utama mengapa penulisan skripsi ini menjadi hal yang harus dilalui oleh mahasiswa sebelum menyelesaikan studinya, pertama sebagai bukti bahwa mahasiswa tersebut kompeten di bidang keilmuannya, karena mahasiswa telah teruji secara formal oleh tim penguji. Kedua sebagai bentuk penyebaran keilmuan yang telah diperoleh selama studi, karena karya ilmiah merupakan karya yang dapat dipelajari dengan mudah dan cepat khususnya pada era digital ini (Putra \& Arkan, 2017), (Pasaribu, 2018).

Namun pada pelaksanaanya, tujuan ini belum tercapai secara maksimal. Mahasiswa masih belum dapat menentukan dan menyusun topik dalam menyusun skripsi dengan baik, terkadang juga ditemui ada topik yang telah dipilih memiliki tinggat kesamaan (plagiat) yang sangat tinggi (Miranti, 2012), (Purnawan, 2018), (Hartanto et al., 2019). Hal ini dikarenakan mereka hanya membaca beberapa skripsi yang sudah ada di perpustakaan kampus dan mengganti lokasi ataupun variabel penelitiannya, namun isi ataupun konten yang diajukan tidak jauh berbeda. Hasil skripsi 
seperti ini, membuat mahasiswa belum dikatakann kompeten dalam bidang keilmuannya, karena belum memberikan kontribusi yang signifikan bagi kemajuan keilmuannya (Siswanto \& Sampurno, 2015).

Wulan, at al (2018) menyatakan bahwa salah satu tantangan di bidang akademisi saat ini adalah maraknya plagiasi yang dilakukan oleh peneliti khususnya oleh mahasiswa yang sedang menyelesiakan tugas akhir. Akhirnya dilakukan pendeteksian hasil skripsi mahasiswa menggunakan metode N-Grams dan Winnowing. Di samping itu, Handayaningsih \& Pujiyono (2010) juga telah melakukan kegiatan pendampingan kepada 256 mahasiswanya dengan sistem konsultasi dan laporan pembimbingan tugas akhir. Hal ini dilakukan untuk menghindari kesulitan menyusun skripsi. Namun, melakukan pendeteksian terhadap hasil plagiasi tidak cukup jika belum dilakukan tindaklanjut terhadap hasil tersebut.

Mengatasi masalah di atas, perlu adanya pendampingan ataupun pelatihan untuk memberikan wawasan tambahan kepada mahsiswa mengenai bagaimana memilih dan menentukan topik baru yang sedang berkembang sesuai dengan keilmuannya. Perlu dilakukan pelatihan mengenai strategi menyusun skripsi, menelusuri atau memilih referensi yang relevan dan ter-update, serta bagaimana mengetahui bahwa skripsi yang mereka kerjakan adalah suatu hasil penelitian yang baru atau hanya hasil plagiasi dari karya sebelumnya (Nurisani, Wulandari, \& Sundari, 2019).

Pemerintah sudah menyediakan referensi berbasis digital melalui laman http://garuda.ristekbrin.go.id/ yang bisa dimanfaatkan oleh mahasiswa dalam menelusuri penelitian yang relevan dengan topik yang mereka angkat. Disamping itu, kegiatan ini dilakukan untuk mengetahui penggunaan aplikasi Mendeley dalam menyusun referensi, dimana software ini sangat praktis dan mudah digunakan oleh penulis khususnya pemula. Penggunaan Mendeley akan memudahkan penulis dalam menyusun rujukan yang valid dan teratur. Penggunaan mendeley akan memudahkan penulis dalam mengorganisasikan dokumen dan rujukan, menjelajahi berbagai referensi yang disarankan, menyusun daftar pustaka dan mengurutkannya, serta membuat sitasi (Kuntarto, 2012), (Hartanto et al., 2019). Pernyataan ini sejalan hasil pelatihan yang dilakukan oleh Setiawan, Hamzah, \& Arlenny, (2019) yang menyatakan bahwa Mendeley adalah perangkat lunak pengelola sitasi atau referensi yang cepat dan rapi, serta penulis dapat mengelola sumber-sumber bacaan yang digunakan sebagai referensi atau acuan dalam menyusun tulisannya.

Oleh sebab itu, tujuan dilakukan kegiatan ini adalah (1) untuk memudahkan mahasiswa menelusuri hasil-hasil penelitian relevan berbasis digital seperti database Portal Garuda, Google Scholar, DOAJ, dan ScienceDirect; (2) untuk memudahkan mahasiswa dalam menuliskan rujukan dan daftar pustaka menggunakan aplikasi Mendeley; (3) untuk meningkatkan pemahaman mahasiswa tentang aplikasi Plagiarism Checker guna mengurangi tingkat plagiasi yang dilakukan oleh mahasiswa.

\section{METODE PELAKSANAAN}

Kegiatan ini dilakukan berbasis workshop. Dimana para peserta mendengarkan serta langsung praktik apa yang dijelaskan oleh pemateri yang dalam hal ini tim Abdimas. Peserta yang terlibat dalam kegiatan ini sebanyak 80 orang. Adapun tahapan yang dilakukan untuk menyukseskan kegiatan ini sebagai berikut:

1. Menyiapkan lembar kerja yang berisi tentang: (a) menentukan dosen pembimbing, (b) menentukan topik/judul penelitian, (c) menentukan hasil penelitian relevan, menentukan pendahuluan penelitian, (e) menentukan kajian pustaka terkait variable penelitian, (f) menentukan metode penelitian terkait jenis penelitian, subjek penelitian, instrument yang digunakan, dan metode penelitian.

2. Menyampaikan materi tentang strategi penentuan dosen pembimbing. Hal ini dilakukan untuk mempermudah mahasiswa dalam menentukan pilihan pembimbing yang akan diajukan kepada Komisi Skripsi. Mahasiswa akan menelusuri rekam jejak para dosen melalui akun Google Scholarnya (https://scholar.google.co.id/).

3. Menyampaikan materi tentang strategi menelusuri hasil-hasil penelitian yang relevan dengan topic penelitian mahasiswa melalui laman Portal Garuda (http://garuda.ristekbrin.go.id/). Mahasiswa diminta menentukan minimal 5 hasil penelitian yang relevan.

4. Melakukan pembagian kelompok sesuai peminatan mahasiswa berdasarkan jenis penelitian yakni kualitatif, kuantitatif, dan penelitian pengembangan (R\&D). Diskusi ini didampingi oleh masing-masing dosen yang kompeten guna mendiskusikan judul atau topic penelitian yang diajukan oleh mahasiswa berdasarkan 
hasil penelusuran di Portal Garuda dan Google Scholar.

5. Menyampaikan materi tentang penggunaan aplikasi Mendeley dalam menulis rujukan dan menyusun daftar pustaka dengan baik dan benar.

6. Menyampaikan materi tentang penggunaan aplikasi Plagiarism Checker sebagai gambaran untuk menghindari kegiatan plagiasi oleh mahasiswa serta cara memperbaiki plagiasi yang terdeteksi oleh aplikasi tersebut.

7. Melakukan feedback terhadap hasil pengerjaan mahasiswa. Pada tahap ini dilakukan diskusi lepas atau Tanya jawab antara pemateri dengan mahasiswa agar hal-hal yang belum jelas dan masih menjadi kebingungan mahasiswa diselesaikan dengan baik.

8. Melakukan penyebaran angket menggunakan Google Form kepada para peserta untuk melihat kualitas hasil pelaksanaan kegiatan ini meliputi tingkat pemahaman dan kemampuan mahasiswa terhadap hasil workshop serta materi yang belum dipahami dengan sempurna sehingga akan ditindaklanjuti pada kegiatan selanjutnya.

\section{HASIL DAN PEMBAHASAN Kondisi Workshop}

Kegiatan awal adalah menyampaikan materi tentang strategi penyusunan proposal skripsi terkait pemilihan topic penelitian, pendahuluan, kajian pustaka, dan metode penelitian. Pada tahap ini disampaikan pula teknik penelusuran referensi dari Portal Garuda dan Google Scholar. Para peserta sangat antusias mendengarkan materi sehingga tidak sedikit yang langsung bertanya ketika ada hal penting yang belum dipahami. Adapun kondisi penyampaian materi terlihat pada Gambar 1 berikut.

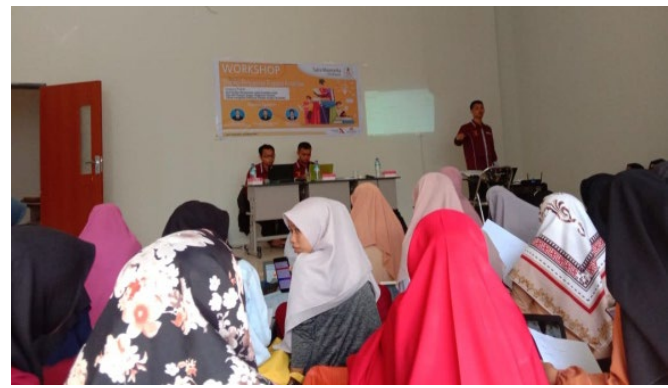

Gambar 1. Proses Penyampaian Materi

Selanjutnya, tim Abdimas membagi kelompok menjadi 3 berdasarkan pilihan jenis penelitian peserta yakni kualitatif, kuantitatif, dan pengembangan. Tim Abdimas juga membagikan lembar kerja untuk dikerjakan oleh para peserta. Pada tahap ini, para peserta berdiskusi dengan pemateri untuk menentukan topic penelitian terbaik untuk dipilih dari berbagai sumber referensi yang dilacak dari Portal Garuda dan Google Scholar. Para peserta mengerjakan lembar kerja sampai tuntas. Topic yang diajukan oleh peserta juga dipertimbangkan dengan judul-judul skripsi yang sudah diajukan oleh mahasiswa pada tahun sebelumnya untuk menghindari kemiripan judul skripsi. Adapun kondisi diskusi kelompok terlihat pada Gambar 2 berikut.

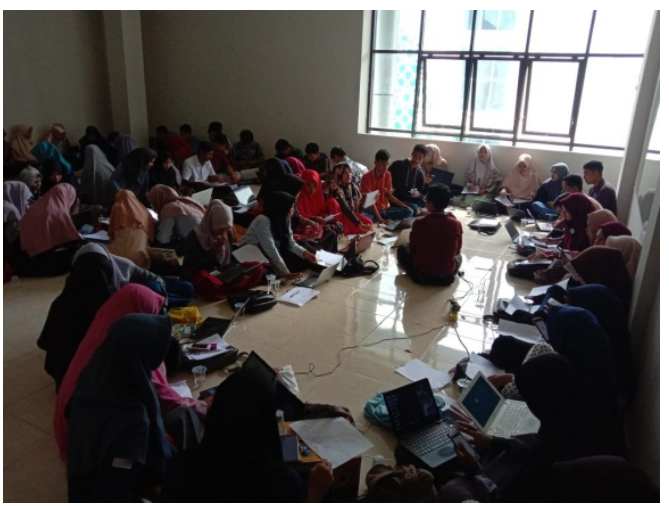

Gambar 2. Suasana Diskusi Peserta

Pada Gambar 2 di atas terlihat diskusi berjalan dengan lancar, dimana dosen membimbing mahasiswa untuk menentukan topik yang sesuai keinginan, terupdate, dan didukung oleh hasil-hasil penelitian yang relevan. Selanjutnya, tahap diskusi ini ditutup dengan Tanya jawab terkait metode penelitian yang sesuai dari judul-judul yang diajukan.

Pada tahap berikutnya, pemateri menyampaikan materi penggunaan aplikasi Mendeley. Dimana pada tahap ini, para peserta langsung praktik mulai dari register dan instalasi aplikasi Mendeley secara online, sampai praktik mengoperasikannya. Tanggapan dari peserta sangat baik karena selama ini mereka hanya menulis rujukan dan daftar pustaka secara manual. Selanjutnya, pada tahap akhir, pemateri menyampaikan materi tentang penggunaan aplikasi Plagiarism Checker untuk mendeteksi kegiatan plagiasi yang dilakukan oleh mahasiswa. Pemateri memberikan simulasi contoh paper menggunakan aplikasi ini. Hasil pengecekan plagiat dijelaskan maksudnya kepada peserta serta bagaimana teknik memperbaiki proposal atau paper jika terdeteksi sebagai hasil plagiasi agar mahasiswa memiliki pemahaman dan kemampuan untuk memperbaiki proposal sendiri tanpa harus membuat ulang proposal yang sudah disusunnya. 


\section{Tanggapan Peserta}

Setelah seluruh materi disampaikan dengan baik, selanjutnya pemateri membagikan angket secara online berbasis Google Form untuk melihat tingkat pemahaman dan kemampuan para peserta terhadap materi dan aplikasi yang sudah diajarkan. Disamping itu, angket ini bertujuan untuk melihat kekurangan-kekurangan yang belum dikuasai oleh para peserta untuk ditidaklanjuti baik bentuk diskusi formal maupun non-formal nantinya. Angket terdiri dari 7 item pernyataan tentang pemahaman dan kemampuan pseserta dengan Skala Likert 4 option yakni Sangat Paham (SP), Paham (P), Cukup Paham (CP), dan Tidak Paham (TP). Adapun hasil angket sesuai Tabel 1 berikut.

Tabel 1. Tingkat Pemahaman dan Kemampuan Peserta Workshop

\begin{tabular}{|c|c|c|c|c|c|}
\hline \multirow[b]{2}{*}{$\begin{array}{l}\mathbf{N} \\
\mathbf{0}\end{array}$} & \multirow{2}{*}{$\begin{array}{c}\text { Pernyataan } \\
\text { Pemahama } \\
\text { n dan } \\
\text { Kemampua } \\
\text { n }\end{array}$} & \multicolumn{4}{|c|}{ Persentase } \\
\hline & & SP & $\mathbf{P}$ & $\mathrm{CP}$ & TP \\
\hline 1 & $\begin{array}{l}\text { Menentukan } \\
\text { judul } \\
\text { penelitian }\end{array}$ & $9,8 \%$ & $\begin{array}{c}58,5 \\
\%\end{array}$ & $\begin{array}{c}31,7 \\
\%\end{array}$ & $0 \%$ \\
\hline 2 & $\begin{array}{l}\text { Membedaka } \\
\mathrm{n} \text { jenis } \\
\text { penelitian }\end{array}$ & $39 \%$ & $\begin{array}{c}46,3 \\
\%\end{array}$ & $\begin{array}{c}14,6 \\
\%\end{array}$ & $0 \%$ \\
\hline 3 & $\begin{array}{l}\text { membuat } \\
\text { rumusan } \\
\text { masalah, } \\
\text { tujuan dan } \\
\text { manfaat } \\
\text { penelitian }\end{array}$ & $\begin{array}{c}12,2 \\
\%\end{array}$ & $\begin{array}{c}51,2 \\
\%\end{array}$ & $\begin{array}{c}29,3 \\
\%\end{array}$ & $7,3 \%$ \\
\hline 4 & $\begin{array}{l}\text { Menentukan } \\
\text { uji statistik } \\
\text { yang } \\
\text { digunakan } \\
\text { untuk } \\
\text { menjawab } \\
\text { hipotesis }\end{array}$ & $2,4 \%$ & $\begin{array}{c}43,9 \\
\%\end{array}$ & $\begin{array}{c}43,9 \\
\%\end{array}$ & $9,8 \%$ \\
\hline 5 & $\begin{array}{l}\text { Menelusuri } \\
\text { referensi } \\
\text { atau hasil } \\
\text { penelitian } \\
\text { relevan } \\
\text { berbasis } \\
\text { digital } \\
\text { (online). }\end{array}$ & $\begin{array}{c}34,1 \\
\%\end{array}$ & $\begin{array}{c}34,1 \\
\%\end{array}$ & $\begin{array}{c}29,3 \\
\%\end{array}$ & $2,4 \%$ \\
\hline 6 & $\begin{array}{l}\text { Menggunak } \\
\text { an aplikasi } \\
\text { Mendeley } \\
\text { dalam } \\
\text { menuliskan } \\
\text { daftar } \\
\text { pustaka }\end{array}$ & $4,9 \%$ & $22 \%$ & $39 \%$ & $\begin{array}{c}34,1 \\
\%\end{array}$ \\
\hline 7 & $\begin{array}{l}\text { Menggunak } \\
\text { an aplikasi } \\
\text { Plagiarism } \\
\text { Checker. }\end{array}$ & $\begin{array}{c}12,2 \\
\%\end{array}$ & $\begin{array}{c}51,2 \\
\%\end{array}$ & $\begin{array}{c}29,3 \\
\%\end{array}$ & $7,3 \%$ \\
\hline
\end{tabular}

Berdasarkan Tabel 1 di atas, terlihat bahwa mahasiswa sangat paham ratarata sebesar $16,37 \%$, mahasiswa paham ratarata sebesar $43,89 \%$, mahasiswa cukup paham rata-rata sebesar $31,01 \%$, mahasiswa tidak atau belum paham rata-rata sebesar $8,7 \%$. Hasil ini membuktikan bahwa kegiatan ini belum sepenuhnya berhasil dilaksanakan. Karena masih ada mahasiswa yang belum paham sepenuhnya sebesar $39,71 \%$. Sehingga oleh tim Abdimas perlu dilakukan kegiatan lanjutan untuk memaksimalkan pemahaman dan kemampuan mahasiswa dalam strategi menyelesaikan tugas akhir. Adapun point-point yang belum dikuasai secara maksimal oleh mahasiswa yakni pada point menentukan uji statistik yang digunakan untuk menjawab hipotesis. Hasil ini diperoleh dari peserta yang memilih kuantitatif sebagai jenis penelitian yang diajukan.

\section{Tindaklanjut Kegiatan}

Hasil angket yang telah disebarkan diperoleh tingkat pemahaman mahasiswa terhadap variabel dalam kegiatan ini sesuai Gambar 3 berikut.

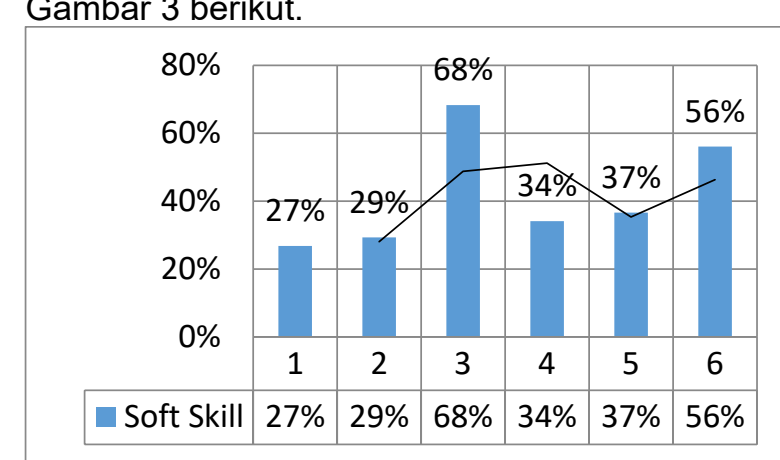

Gambar 3. Gambaran Umum Tingkat Soft Skill Peserta

Berdasarkan Gambar 3 di atas, maka dilakukan beberapa tindaklanjut dari kegiatan ini agar dipeorleh hasil yang maksimal, yakni:

1. Melakukan kegiatan lanjutan terkait penggunaan aplikasi Mendeley dalam menulis rujukan dan menyusun daftar pustaka yang waktu disesuaikan kesepakatan bersama antara peserta dan pemateri.

2. Membuat grup WhatsApp untuk diskusi lebih lanjut bersama pemateri sehingga para peserta bias bertanya sebanyak mungkin yang belum jelas terkait penelitian dan penyusunan skripsi.

\section{SIMPULAN DAN SARAN}

Peningkatan soft skill mahasiswa untuk mengetahui dan menguasai strategi penyusunan tugas akhir sangat penting. Hal ini bertujuan untuk memudahkan mereka dalam menelusuri hasil penelitian relevan yang mendukung penelitian yang mereka ajukan. Di samping itu, kegiatan plagiasi yang dilakukan oleh mahasiswa bias diminimalisir. Hasil kegiatan yang telah dilaksanakan diperoleh 
hasil sebanyak 91,27\% mahasiswa sudah paham terhadap strategi penyusunan dan menyelesiakan tugas akhir, sedangkan sisanya belum paham sebesar $8,73 \%$. Ketidakpahaman ini terjadi pada bagian menentukan uji statistik yang digunakan untuk menjawab hipotesis penelitian.

Oleh sebab itu, tim Abdimas menyarankan untuk kegiatan selanjutnya pembahasan lebih detail tentang uji hopitesis yang digunakan dalam menjawab hipotesis untuk kasus hubungan, korelasi, efektivitas, komparasi, pembandingan, ataupun perbedaan.

\section{UCAPAN TERIMA KASIH}

Tim Abdimas mengucapkan terima kasih kepada pihak yang telah membantu dalam menyukseskan kegiatan ini yakni Himpunan Mahasiswa Jurusan (HMJ) Tadris Matematika UIN Mataram yang telah berperan dalam kepanitiaan. Serta Tim Abdimas yang solid dari Universitas Muhammadiyah Mataram, Universitas Bumigora Mataram, Universitas Nahdlatul Wathan Mataram dan Universitas Nahdlatul Ulama NTB.

\section{DAFTAR RUJUKAN}

Handayaningsih, S., \& Pujiyono, W. (2010). Sistem Konsultasi Dan Laporan Pembimbingan Tugas Akhir. Seminar Nasional Informatika Yogyakarta, 2010(semnasIF), 197-204.

Hartanto, D., Rengga, W. D. P., Bahlawan, Z. A. S., Pradnya, I. N., Sammadikun, W., \& Sutrisno, A. (2019). Pelatihan Aplikasi Turnitin Dan Mendeley Software Bagi Mahasiswa Unnes Dalam Rangka Peningkaatan Kompetensi. Amaliah: Jurnal Pengabdian Kepada Masyarakat. https://doi.org/10.32696/ajpkm.v3i1.23 9

Kuntarto, E. (2012). Teknik Menyusun Sitasi Otomatis dengan Software Mendeley. Pascasarjana Universitas Jambi.

Miranti, V. A. (2012). Internet Plagiarism di Kalangan Mahasiswa (Studi Fenomenologi Tentang Motif Internet Plagiarism Di Kalangan Mahasiswa. ADLN - Perpustakaan Universitas Airlangga, 90-112.

Nurisani, R., Wulandari, E. R., \& Sundari, Y. (2019). Perilaku Penggunaan Aplikasi Sitasi Mahasiswa (Studi Kasus di Program Studi Pascasarjana Fikom Unpad 2018). Pustabiblia: Journal of Library and Information Science. https://doi.org/10.18326/pustabiblia.v3i 1.74-88

Pasaribu, B. S. (2018). Hubungan Tingkat Stres
Volume 3, Nomor 2, Mei 2020. p-ISSN : 2614-5251 e-ISSN : 2614-526X

dengan Motivasi Mahasiswa Mengerjakan Skripsi di Fakultas Kesehatan Masyarakat USU. Skripsi, Universitas Sumatera Utara.

Purnawan, A. (2018). Penanaman Perilaku Anti-Plagiasi Dalam Perkuliahan Writing For Academic Assignments. Diksi, 25(1).

https://doi.org/10.21831/diksi.v25i1.16 009

Putra, G. B., \& Arkan, F. (2017). Implementasi Sistem Bimbingan Tugas Akhir Mahasiswa Berbasis Web Server Dan Android. E-Issn:2541-2361, Issn 25412361, 02(01), 137-145.

Setiawan, D., Hamzah, H., \& Arlenny, A. (2019). Pelatihan Ms. Word \& Mendeley Untuk Penulisan Karya IImiah Dosen Fakultas Teknik Unilak. Dinamisia: Jurnal Pengabdian Kepada Masyarakat. https://doi.org/10.31849/dinamisia.v3i1 .2215

Siswanto, I., \& Sampurno, Y. G. (2015). FaktorFaktor Penghambat Pengerjaan Tugas Akhir Skripsi Mahasiswa Pendidikan Teknik Otomotif Ft Uny. Taman Vokasi, 1(1). https://doi.org/10.30738/jtvok.v3i1.313

Wulan, F. R. N., Kunaefi, A., \& Permadi, A. (2018). Deteksi Plagiasi Dokumen Skripsi Mahasiswa Menggunakan Metode N-Grams Dan Winnowing. Simetris: Jurnal Teknik Mesin, Elektro Dan IImu Komputer, 9(2), 1021-1032. https://doi.org/10.24176/simet.v9i2.253 5 